\title{
MUSEUS DE GRANDES NOVIDADES: CENTROS CULTURAIS E SEU PÚBLICO
}

\section{Lígia Dabul \\ Universidade Federal Fluminense - Brasil}

Resumo: Nesse artigo analiso a presença do chamado grande público em exposições de artes plásticas. Primeiro enfoco a proliferação, a partir da década de 1970, de centros culturais e de instituições com algumas de suas características, onde parte considerável das exposições voltadas para esse público é oferecida. Em seguida, abordo dimensões políticas desse afluxo registradas em estudos sociológicos a respeito do contato da população com objetos de arte legitimados pelas classes privilegiadas. Finalmente, baseados em pesquisa etnográfica, reflito sobre as especificidades e as continuidades das exposições de artes plásticas frente a outras situações de apresentação de produtos artísticos, atentando para o significado da presença do público nelas e para conseqüencias analíticas de seu estudo.

Palavras-chave: arte, centros culturais, exposições de arte, público.

Abstract: In this article, we analyze the attendance of what we call the general public in plastic art exhibitions. At first, we put in focus the spread of cultural centers or institutes with some of its characteristics, since the 1970 decade, where a great number of exhibitions directed to this kind of public take place. After that, we approach the political importance of this flowing registered in sociological studies concerning people being in touch with art objects legitimated by affluent people. Finally, based on ethnographic research, we reflect on the fact of the plastic art exhibitions be specific and continuous before other situations of artistic products presentation, observing the sense of the public attendance in the exhibitions and the analytical consequences of their study.

Keywords: art, art exhibitions, cultural centers, public. 
eu vejo o futuro repetir o passado eu vejo um museu de grandes novidades

Cazuza e Arnaldo Brandão

A presença do público em exposições de arte em centros culturais suscita reflexões, ânimos e ponderações de cientistas sociais, de movimentos sociais, de agentes do Estado e do chamado mundo artístico. Isso tanto por conta do número já há algum tempo grande e cada vez maior de pessoas que freqüen$\operatorname{tam}^{1}$ essas exposições como pelos contornos inusitados que a presença do público nelas vem adquirindo. Esse contato da população com objetos de arte tradicionalmente apresentados para as classes privilegiadas é acompanhado de algumas surpresas. Em primeiro lugar, coloca em questão um vetor que perpassa essas exposições, voltado preferencialmente para os olhos dessas classes privilegiadas. Ainda, a presença de novos atores sociais sugere, projeta, possibilidades de contato com objetos de artes plásticas que se afastam dos procedimentos solenes e educativos freqüentemente preconizados, ou idealizados, como constitutivos da experiência estética.

O contingente de indivíduos que afluem a exposições de artes plásticas em centros culturais conforma um público crescente, diversificado, atraído por igualmente crescente e diversificada oferta dessas exposições em locais mais e mais acessíveis e centrais, incorporadas a atividades escolares, tratadas especialmente pela mídia, a baixos custos ou gratuitas, e inseridas cada vez mais em espaços capazes de abrigar atividades outras de lazer e outros serviços. A valorização e difusão de centros culturais acompanham esses processos e a muito freqüente variação do termo (centro cultural, centro de arte, casa de cultura, espaço cultural, shopping cultural, ${ }^{2}$ etc.) e das ações dos que viabilizam

\footnotetext{
Por exemplo, já em 1995, no Centro Cultural Banco do Brasil (1995) o público estimado foi de 190 mil pessoas por mês e 2,3 milhões por ano. As visitas ao Masp (Barbosa, A. C., 1994, f. 74) foram 100 mil em 1990, 140 mil em 1991, 162 mil em 1992 e 160.295 até novembro de 1993. Cifras relativas a outros centros culturais e museus de arte confirmam esse enorme e crescente afluxo de público a exposições de arte em espaços públicos das grandes cidades.

2 Ver em Mello e Silva (1995, p. 79) descrição de atividades do Shopping Cultural Fundição Progresso, no Rio de Janeiro. Ver em Gondim (2000, p. 27) depoimento de arquiteto que acompanhou a obra do Centro Dragão do Mar de Arte e Cultura, em Fortaleza: “[...] a idéia é essa: de um grande shopping de cultura, sem o lado depreciativo do que é o shopping center hoje. É você transformar essas atrações, uma coisa linear, interligada, que recomponha um pouco [...] das condições do espaço urbano, onde você tem ruas de pedestre, bar, estacionamento em áreas chave, tem várias entradas... Agora, tudo isso é interligado por uma passarela, que faz o link”.
}

Horizontes Antropológicos, Porto Alegre, ano 14, n. 29, p. 257-278, jan./jun. 2008 
política e materialmente sua criação ${ }^{3}$ de algum modo corresponde à multiplicidade de atividades, interesses e eventos que ocorrem nesses espaços.

Um conjunto grande de itens que caracterizavam e distinguiam os centros culturais dos museus de arte, como a diversidade de atividades oferecidas, foram também, com o tempo, incorporados por eles. De outro lado, os atributos que tradicionalmente singularizavam os museus de arte frente a outros espaços e instituições que promovem exposições de objetos artísticos, como muitos pesquisadores vêm demonstrando, hoje não os diferenciam mais. Profissionais e estudiosos de museus, por exemplo, já incorporaram diversas outras instituições ao redefinirem a categoria museu em 2001, numa assembléia geral do International Council of Museums (ICOM), nela agora incluindo também “centros culturais e outras entidades voltadas à preservação, manutenção e gestão de bens patrimoniais tangíveis e intangíveis” (Loureiro, 2004, p. 97) Assim, possuir ou não possuir acervo deixou de ser um item constitutivo dos critérios para estabelecer extensamente essa categoria. No Centro Dragão do Mar de Arte e Cultura, em Fortaleza, o acervo de peças está alocado no denominado Memorial da Cultura Cearense, o Museu de Arte Contemporânea apresentando sempre conjuntos ou coleções cedidos provisoriamente, em exposições temporárias.

Voltados tradicionalmente para a exposição de seus acervos, parte importante dos museus tem hoje em dia suas atividades diversificadas, nesse sentido acompanhando o "formato" que os centros culturais já no seu surgimento possuíam. Muitos museus, de fato, e em especial os chamados museus de arte, para além dos espaços destinados, por exemplo, à alimentação e venda de objetos, organizam espaços para atividades de outro tipo, não voltadas diretamente para a exposição de seus acervos ou de objetos, mas para aquelas como cinema, música, teatro, dança, leitura e pesquisa. Embora hoje generalizada, a tendência de multiplicação e aglutinação de atividades em um mesmo espaço coincidiu de fato com o surgimento dos chamados centros culturais. Segundo Milanesi (1990, p. 21-22) e outros pesquisadores, a disseminação de centros culturais deu-se a partir da década de 1970, estimulada pela construção e criação, em 1975, do Centro Cultural Georges Pompidou, o Beaubourg, em Paris, com cerca de 25 mil pessoas dirigindo-se a ele diariamente, um dos lugares

3 Ver, a respeito dessas ações, Milanesi (1990). 
mais visitados da França. ${ }^{4}$ Um número imenso de centros culturais, em diversos países, por diferentes razões e processos foram então construídos, como o Barbican Center, em Londres, a Biblioteca Pública e Complejo Cultural Mariano Moreno, em Buenos Aires, e o Lincoln Center, em Nova Iorque, dentre muitos e muitos outros. Numerosos centros culturais foram construídos também no Brasil, como o Centro Cultural São Paulo, a Biblioteca Pública do Estado do Rio de Janeiro, o Espaço Cultural José Lins do Rego, em João Pessoa, Paraíba, o Centro de Criatividade de Aracaju, Sergipe. Mas centros culturais foram igualmente criados a partir da restauração de prédios antigos, da ocupação de prédios disponíveis, da ocupação de parte de prédios com outras funções, incorporadas, como biblioteca, ou não, ao centro cultural (Milanesi, 1990, p. 35-36).

A diversidade de atividades concentradas nos centros culturais e, depois também, nos museus de arte, marca muitas vezes de maneira bem clara sua própria arquitetura. O Beaubourg, por exemplo, abriga, além do Musée National d'Art Moderne, com 15 mil metros quadrados e espaço para exposições periódicas, para encontros e debates, para exibição de audiovisuais e para serviço de documentação artística, a Bibliothèque Publique d'Information, com 15 mil freqüentadores diários, o Centre de Création Industrielle, com espaço para galerias de exposições e local para encontros e debates, o restaurante, o centro de acolhimento, etc. Diferindo, de fato, do que até então museus e bibliotecas costumavam ser, os centros culturais desde sua criação agregaram múltiplas atividades, como cinema, teatro e música, exposições e leituras, que antes tendiam a existir em instituições isoladas. O público que aflui a esses centros, por certo também devido a essas distintas atividades oferecidas, é especialmente diversificado, contrastando com o público relativamente homogêneo que nos grandes centros urbanos freqüentava e freqüenta cada uma dessas instituições, sobretudo quando isoladas umas das outras. ${ }^{5}$

${ }^{4}$ O Beaubourg de fato abriu suas portas para o público em 1977 (Piano; Rogers, 1987, p. 9). Para outros pesquisadores, como Prazeres (1996, f. 45), essa difusão de centros culturais teria ocorrido sobretudo na década de 1980 .

5 Há, por parte da administração de museus e de centros culturais, a constatação de que os seus freqüentadores são também, muitas vezes, os que estão no "teatro, cinema, concertos, os que lêem livros e os que têm como hábito freqüentar outras atividades culturais” (Carvalho, 1999, p. 2). Essa constatação, em alguns casos, seria revertida para o esforço de muitas instituições deste tipo no sentido de obterem recursos importantes para sua manutenção, ou mesmo para tornarem-se autosuficientes financeiramente, questão em pauta hoje em dia e veiculada com certa freqüência pela própria imprensa. A atração do público nesses casos, assim, estaria também voltada para a geração de receita.

Horizontes Antropológicos, Porto Alegre, ano 14, n. 29, p. 257-278, jan./jun. 2008 
A relativa heterogeneidade do público das exposições de centros culturais e de muitos museus de arte, bem como a gama extensa de atividades virtualmente associadas a essas visitas já ali, no local em que são organizadas, ${ }^{6}$ fazem com que estudar a presença do público nessas exposições corresponda a pensar nos limites que costumamos utilizar para recortar a arte, levando em conta as interações e práticas sociais constitutivas e associadas a essa presença do público em exposições. São, de fato, como já indicado, numerosas e variadas as atividades, ou práticas culturais, como apresentações, leituras, exposições, que já há algumas décadas percebe-se estarem vinculadas às visitas assíduas a museus de arte (Giraudy; Bouilhet, 1990, p. 90), porque levadas a cabo com freqüência, embora noutros espaços, pelo público de museus. Pesquisa encomendada pelo Centro Cultural Banco do Brasil Rio de Janeiro (1995) ${ }^{7}$ constatou que uma razão fundamental apresentada pelo público para justificar sua freqüência àquele centro cultural, em detrimento de outros espaços "culturais" da cidade do Rio de Janeiro, é exatamente a multiplicidade de atividades oferecidas por ele.

Além da concentração de eventos no espaço, centros culturais e museus de arte recentemente criados apresentam mais e mais a sua alocação em lugares centrais da cidade. Barbosa, A. C. (1994, f. 80) aponta como a localização do Masp propicia a convergência do público:

O Masp é uma importante referência urbana da cidade. Lá estudantes, amigos e namorados se encontram para irem ao próprio museu ou a algumas das muitas opções culturais que a região da Avenida Paulista oferece: dezenove cinemas, o Centro Cultural Casa das Rosas e o Instituto Cultural Itaú.

6 Essa associação de atividades por vezes chega a ser institucionalizada. No Centro Cultural Banco do Brasil do Rio de Janeiro, por exemplo, há as chamadas "visitas casadas", com atividades promovidas pela instituição a partir de visitas a dois eventos do Centro Cultural (Centro Cultural Banco do Brasil, 2003, p. 3). No caso do Centro Dragão do Mar de Arte e Cultura, é comum a associação da ida de visitantes, acompanhados de guias, a duas exposições fixas, por vezes seguidas de uma visita a mais uma, temporária. Também no Museu Internacional de Arte Naïf do Brasil, no Rio de Janeiro, a conjugação de visitas monitoradas ao acervo e a exposições temporárias é comum e organizada pelo próprio museu.

7 O Centro Cultural Banco do Brasil também foi instalado em São Paulo, Brasília e Recife. Mas, sempre que me referir a Centro Cultural Banco do Brasil neste trabalho, estarei tratando do que funciona na cidade do Rio de Janeiro.

Horizontes Antropológicos, Porto Alegre, ano 14, n. 29, p. 257-278, jan./jun. 2008 
K. Hansen (2003, p. 1) propõe que a localização de centro cultural, no caso o Centro Cultural Banco do Brasil, no Rio de Janeiro, favoreceria seu caráter "democrático”: “A localização, no centro da cidade [...] é um convite permanente ao público de trabalhadores, estudantes, turistas etc., que circulam pelos arredores, buscam lazer e/ou enriquecer o espírito pelo contato com as diversas manifestações artísticas e culturais.” E adenda fator aglutinador importante do Cultural Banco do Brasil e de número grande desses centros culturais: "O melhor é que a maioria dessas atividades tem entrada franca [...]".

Essa concentração de eventos no mesmo espaço físico, em lugar central, de fácil acesso da cidade, e a preços baixos ou gratuitos, além de propiciar aumento e heterogeneidade de público, favorece a variação, novas configurações na sua presença. Muitas visitas são feitas rapidamente, por exemplo, como espera de alguma atividade para a qual aqueles atores sociais, os visitantes, mobilizaram-se especialmente - um filme, uma peça de teatro, uma performance. É, do mesmo modo, comum que excursões turísticas, organizadas ou não por empresas especializadas, dirijam-se a centros culturais também por conta do valor histórico dos seus prédios, ou monumental deles, a visita à exposição consistindo em uma visita a dependências do prédio e no conhecimento de um tipo de evento oferecido nele. É o caso de tantos, como o Masp, associado por parte do público à cidade de São Paulo, espécie de cartão postal para onde afluem também turistas e visitantes da cidade, independentemente das "atrações" oferecidas, o próprio prédio sendo considerado uma delas (Barbosa, A. C., 1994).

O afluxo a centros culturais e a museus de arte em razão do valor histórico de seus prédios é o que ocorre com freqüência, por exemplo, no Centro Cultural Banco do Brasil, ${ }^{8}$ no Espaço Cultural dos Correios, no Centro Cultural da Light, no Rio de Janeiro. Os três centros culturais foram construídos com aproveitamento e restauração dos prédios de suas antigas sedes. ${ }^{9}$ Mesmo os

${ }^{8}$ No Centro Cultural Banco do Brasil, quando essa pesquisa foi realizada, o Programa Educativo desenvolve o projeto CCBB, Muito Prazer. São visitas guiadas às instalações do prédio. Voltado mais que tudo para grupos de estudantes levados ao Centro Cultural por suas escolas, segundo uma monitora, o objetivo do projeto é "instigar a curiosidade das crianças sobre o centro cultural, sobre a história do próprio banco [do Brasil].”

9 O Centro de Arte Hélio Oiticica, inaugurado em 1996 e situado no centro histórico do Rio de Janeiro, também ocupa prédio histórico restaurado e adaptado às suas novas funções: "O Centro de Arte Hélio Oiticica foi instalado nos moldes dos grandes centros mundiais e está munido com sofisticados equipamentos de segurança, climatização e iluminação. Ocupa uma área de $1.950 \mathrm{~m}^{2}$,

Horizontes Antropológicos, Porto Alegre, ano 14, n. 29, p. 257-278, jan./jun. 2008 
prédios que abrigam museus, em especial os voltados para a arte contemporânea, não se diferenciariam sempre dos construídos ou adaptados para centros culturais. L. Gonçalves (2004, p. 66) aponta que, a partir dos anos 1970, foi comum governos passarem a construir ou a remodelar museus: "Os museus passam a ser 'monumentos', ícones da modernização da sociedade, emblemas da identidade cultural urbana, lugar obrigatório para a freqüência turística e de lazer e diversão para o cidadão.” Segundo Loureiro (2004, p. 98), referindo-se a museus, a "adaptação de palácios e prédios históricos cede lugar a projetos arquitetônicos arrojados, que já não se limitam a abrigar museus e seus acervos, mas se expõem como verdadeiras obras de arte." ${ }^{10}$ De fato, a criação de centros culturais coincide com a tendência mundial de construção de museus monumentais, que, além de estarem voltados para receber um público bem maior, concentram atividades as mais diversas - livrarias, restaurantes, lojas, bibliotecas, etc. -, tornando-se também, eles mesmos, objeto de atração do público.

\section{Significados desse afluxo}

A presença do público em exposições de arte, sobretudo das classes populares, suscita, tanto para atores envolvidos com a política cultural e com a viabilização dessa presença como para os cientistas sociais que estudam esse afluxo, questões de ordem política, de desdobramento desses fenômenos e de sua inserção em outros de natureza abrangente. Essas questões permeiam objetivos e o encaminhamento de muitas análises sobre o interesse e a participação do público nessas exposições.

sala de conferências, o escritório do Corredor Cultural, a livraria Dazibao, o restaurante Bistrô do Hélio, a loja de gravuras e moldura Sérgio Porto, o setor de documentação e reserva técnica para o acervo do artista Hélio Oiticica.” (Klabin, 1998, p. 138).

${ }^{10}$ Loureiro (2004, p. 98) registra o quanto a suposta descaracterização do museu de arte mobilizou a opinião pública, citando ponto de vista de Kimmelman, veiculado no Jornal do Brasil em 2001: "os museus de arte contemporânea seriam encarados como as 'novas catedrais' do nosso tempo, e a arquitetura como a solução para muitos dos problemas de uma instituição em crise, cuja aparência exterior se converte em um dos únicos aspectos cuja autoridade institucional não tenha sofrido desgaste. As novas prioridades do museu fazem de Bilbao um caso emblemático, e da 'casca vazia', uma metáfora adequada, pois a posse de uma coleção torna-se dispensável.”

Horizontes Antropológicos, Porto Alegre, ano 14, n. 29, p. 257-278, jan./jun. 2008 
Uma dessas questões diz respeito à capacidade efetiva, e daí à própria legitimidade, de indivíduos oriundos das classes populares participarem de situações como as exposições de objetos de arte e, mais ainda, dessas exposições serem concebidas e produzidas em função de sua participação nelas. Parte considerável dos estudos sobre a recepção está de fato marcada pela discussão sobre a possibilidade ou impossibilidade das classes populares terem direito ao acesso e "receberem" conteúdos e mensagens veiculadas em exposições de arte. P. Burke (1989), por exemplo, em trabalho bastante conhecido, ao demonstrar que a "recepção popular não é folha em branco", enfatiza o quanto a concepção negativa da "recepção" mascara o verdadeiro processo de reapropriação e recriação embutido, de algum modo, nas diferentes experiências de "recepção".

Pierre Bourdieu estabelece mais claramente essa relação entre a possibilidade de os indivíduos partilharem a lisibilidade dos objetos apresentados em exposições de arte, marcadamente as de museus, e a sua origem social. Em Gostos de Classe e Estilos de Vida (Bourdieu, 1983), analisa essa relação remetendo-a à capacidade diferenciada dos indivíduos adquirirem o que chama de disposição estética, uma competência e inclinação para reconhecer como artísticos objetos valorizados como tais no campo artístico. Essa disposição estaria assim profundamente vinculada à capacidade de $\mathrm{o}$ ator social ter acesso e manipular o código que classifica esses objetos como artísticos. E, para P. Bourdieu, possuir ou não essa disposição estética distingue, diferencia e localiza o ator social na hierarquia social. ${ }^{11}$

Nathalie Heinich (2000) afirma que estudos como os de P. Bourdieu, que constatam limites para que as classes populares compartilhem linguagem, mensagens e conteúdos dos objetos de arte expostos em museus e galerias, de modo explícito ou não conteriam propostas de extensão às classes populares de instrumentos, sobretudo escolares, que as capacitem para tanto. Mas autores como J.-C. Passeron qualificam essas propostas como "proselitismo" que não teria outra função senão potencializar a legitimidade de obras consagradas. Passeron (1994, p. 327) coloca que é possível “desejar converter o conjunto de

\footnotetext{
${ }^{11}$ Ver em P. Bourdieu e Darbel (1969) a demonstração dessas proposições com os dados de extensa e inauguradora pesquisa sobre o público de museus de arte europeus.
}

Horizontes Antropológicos, Porto Alegre, ano 14, n. 29, p. 257-278, jan./jun. 2008 
uma sociedade à admiração das obras consagradas pela crítica erudita ou pelos conhecedores cultos, tomando como objetivo praticar ao máximo a freqüência e o culto das obras 'legítimas'.” Dessa escolha decorreria, para ele, “uma estratégia de proselitismo voltada para as massas e colocada ao serviço das obras eruditas ou letradas."

De outro lado, cientistas sociais, ao reconhecerem aquela impossibilidade que Bourdieu sublinha e explica, posicionam-se ao lado de numerosos atores sociais que preconizam a promoção da arte produzida pelas classes populares, ao invés da sua instrumentalização para que "consumam” adequadamente a arte erudita, ou de elite. Estaria em jogo a extensão para a chamada arte popular do direito e da oportunidade de ser exposta em circunstâncias e locais valorizados, processo que Passeron considera, dessa vez, uma opção populista. ${ }^{12}$

De toda maneira, a discussão a respeito do investimento deliberado no modo como o público "consome" as obras de arte expostas, sobretudo em locais públicos, é crescente e vem mobilizando artistas, historiadores da arte, críticos, educadores, promotores culturais, curadores. ${ }^{13}$ De certa forma, Nestor García Canclini (1998) acompanha essa tendência de indagar a respeito do processo que chama de "contextualização pedagógica”, denominado por diversos outros atores sociais interessados no "consumo" popular e difusão da arte como "monitoramento”, "arte-educação”, “mediação”, "sensibilização”, etc. Para ele, por meio da contextualização pedagógica, na realidade se estaria tentando "acabar com o monopólio do saber pelos especialistas, dando aos neófitos, em tratamentos acelerados, o que lhes falta para serem artistas ou

12 Jean-Claude Passeron (1994, p. 327) problematiza propostas de desenvolvimento da "expressão autônoma da (ou das) forma/s espontânea/s da (ou das) cultura/s popular/es.”: “E isto pode e já foi experimentado em duas óticas políticas: a) para 'promover' as culturas populares e instaurar para seu benefício uma legitimidade alternativa (seja, nos fatos, pela pressão política; seja, na reivindicação literária ou científica, ao nível único do discurso do intelectual). A forma extrema desta legitimidade de desforra, que se alimenta do desejo dos intelectuais populistas de inverter a legitimidade cultural e às vezes reivindicada com aspereza, provando de passagem seu poder de legitimar o ilegítimo, é então a de uma contralegitimidade; b) para influenciar as representações ou o aparelho de legitimidade cultural existentes numa sociedade para que seus dispositivos simbólicos se diversifiquem e se transformem até acolher em seu seio as produções, estilos e consumos mais característicos das culturas populares. Essas duas opções populistas [...] têm em comum recorrer a uma estratégia de reabilitação das culturas populares, periféricas ou marginais.”

${ }^{13}$ Ver em Barbosa, A. M. (1989) como este debate vem sendo desenvolvido pelos interessados no acesso do grande público a acervos de museus no Brasil.

Horizontes Antropológicos, Porto Alegre, ano 14, n. 29, p. 257-278, jan./jun. 2008 
estarem tão informados quanto eles”; por conta disso, as exposições estariam repletas “de cartazes instrutivos, sinais de trânsito, visitas monitoradas em vários idiomas" (García Canclini, 1998, p. 136), voltados para o entendimento, pelo público, das obras expostas. ${ }^{14}$

Como contextualização pedagógica García Canclini compreende um processo consciente, proposital, de indução do público a uma "leitura” das obras expostas e da exposição, e materializada na própria proposta, muitas vezes rígida, de itinerário de visitas. García Canclini enfatiza como diversos atores sociais, incluindo os que atuam na chamada mídia, envolvem-se nesse esforço pedagógico, o modo como a própria exposição já registra esse esforço, e como o processo de visita é adequado a ele. Contudo, o autor concebe o público como ativo produtor de significados a respeito das exposições que freqüenta. $\mathrm{E}$ demonstra esse ponto de vista com os resultados de extensa pesquisa realizada com o público de museus de arte da cidade do México.

Esse processo de contextualização pedagógica seria, para García Canclini, acompanhado de dois outros: "arrancar as obras de museus e galerias" e "promover oficinas de criatividade popular”. J.-C. Passeron (1994, p. 328, grifo do autor), por seu turno, coloca no horizonte formas mais radicais de promoção da cultura popular do que as que chamou de populistas e dessa proposta de oficinas:

[...] atuando não mais apenas na difusão e no comentário da cultura, mas na própria criação artística, pode-se desejar transformar as formas da produção das obras e até instaurar um campo de interações sociais e simbólicas, onde seria abolida a fronteira entre uma cultura de elite e uma cultura partilhada por todos. [...] A estratégia de tal subversão das ligações costumeiras entre subculturas e grupos sociais só pode ser formulada aceitando-se os meios de uma redefinição revolucionária da cultura e da arte.

\footnotetext{
${ }^{14}$ Frente a essa contextualização pedagógica, García Canclini aponta dois tipos de crítica: a culta e a democrática. A crítica culta afirma que uma contextualização das obras "prejudica a contemplação desinteressada que deveria caracterizar toda a relação com a arte”; a democrática propõe "que a contextualização das obras artísticas aumenta sua legibilidade, mas consegue pouco no que toca à atração de mais espectadores e à incorporação de novos padrões perceptivos” (García Canclini, 1998, p. 137). Essas duas críticas guardam proximidade com pontos de vista, respectivamente, de atores sociais que preconizam um modelo contemplativo de exposições e de atores sociais que propõem um modelo educativo, que será mencionado mais adiante.
}

Horizontes Antropológicos, Porto Alegre, ano 14, n. 29, p. 257-278, jan./jun. 2008 
Essas reflexões políticas e sobre políticas culturais que Passeron e García Canclini desenvolvem permeiam muito fortemente suas - e também muitas outras - análises tanto dos chamados processos de recepção como do acesso mesmo da população às situações onde a arte é apresentada e produzida. Ambos os autores, por meio delas, abrem campo para pensarmos em mecanismos concretos de atores sociais estarem presentes em exposições de arte. A incorporação do olhar sociológico que problematiza o significado social dessas exposições, e particularmente das ações chamadas educativas que nelas se pretende veicular, pode ser feita remetendo a análise para ações sociais concretas do público, e também para as daqueles atores sociais responsabilizados pela atualização de propostas político-pedagógicas associadas às exposições - arte-educadores, curadores e professores, por exemplo.

A idéia de estudo de aspectos sociológicos e políticos das artes plásticas, contudo, não necessariamente valoriza ou visualiza o espaço da exposição, ou ajuda a diluir a própria tendência de conceber a arte como polaridade artista/ público. Essa é uma polarização profundamente inculcada e extensamente compartilhada, ainda na literatura sociológica e na que estuda os chamados processos de recepção, que reconstrói a trajetória de uma mensagem, por meio de seu suposto itinerário artista/objeto/público, e não raro esquece, por exemplo, os mecanismos sociais de produção, seleção e exclusão de mensagens, artistas, objetos e públicos, e, sobretudo, a comunicação estabelecida entre os atores sociais que compõem efetivamente o chamado público. Trata-se de evitar a adesão à noção de exposição como conjuntura de contato do público com mensagens veiculadas por artistas por meio de objetos ali expostos, e de marcar o quanto partir do que os atores sociais efetivamente fazem nos ajuda a recolocar problemas insistentemente tratados pela sociologia, como esse da oportunidade, eficácia e desdobramento de formas da população ter contato com objetos artísticos.

De Certeau é um dos pesquisadores que concebe a chamada recepção como processo ativo, de produção de significado. E confere status de ato social a essa operação do público produzir a obra, sem se limitar a relacioná-la a atributos socioeconômicos dos que participam dessa produção, o que vai de encontro ao modo como exposições de arte podem ser concebidas se a presença do público nelas é ela própria objeto ao qual se pretende chegar. De Certeau (1995) também abre espaço para uma enorme gama de possibilidades de investigação e alarga o campo de observação do que é arte ao conceber o ato concreto de "recriação" em um tempo e em um espaço determinados e envolvidos por atores sociais pensados já nessas situações como coletividade. Esse 
ato concreto, essa prática, é agora a matéria enfocada e valorizada por De Certeau, à qual os atores sociais atribuem sentido. E é por meio dela, dessa prática, que constroem novos sentidos para a arte, não como objeto de "recepção” ou "produção” de significados, mas como situação ela própria significativa para os atores sociais envolvidos. Faríamos atualmente, segundo De Certeau (1995, p. 243, grifo do autor), uma diferenciação maior entre "aquilo que está escrito (o dito) e o gesto que o produz (o dizer)"; essa tendência participaria "da nossa experiência cultural, que refere os sistemas de significados aos procedimentos ou ao ato dos quais eles resultam - o enunciado a uma enunciação”. E remete muito diretamente a produção de significado por "procedimentos e atos” à própria existência dos grupos sociais junto aos quais os atores sociais têm essas experiências artísticas:

Seja como for, esse retorno à produção atribui à expressão sua função de trabalhar na formação ou na renovação de um grupo. Um concerto pop, uma representação teatral, uma manifestação tem como objetivo menos manifestar a verdade imemorial oculta em uma obra do que permitir que uma coletividade se constitua momentaneamente no gesto de se representar. Esse gesto é um desvio em relação às práticas anteriores. É também um ato produtor e, quando coloca em jogo funções diversificadas, não mais obedece à lei que separa os atores dos espectadores. (De Certeau, 1995, p. 243, grifo do autor).

Os significados que essas práticas adquirem, como de resto os atribuídos aos objetos expostos ao público, são consideravelmente variáveis e instáveis. E. Hooper-Greenhill (1992, p. 7) refere-se à “active audience” lembrando como já era concebida nas décadas de 1950 e 1960 nos estudos que demonstram não haver uma recepção fixa, mas atualizada sempre dependendo do contexto em que é feita. Além disso, Hooper-Greenhill dilui o caráter supostamente monolítico e reproduzível do conteúdo da recepção, apresentando-o como elenco flexível de itens, também remissível a contextos específicos.

Na verdade, aqui, o convite mais importante de De Certeau consiste em valorizar aquelas práticas de que fala, e coincide com nosso foco de reflexão no estudo da presença do público nas exposições de objetos de arte, voltado para a compreensão do que seria seu aspecto coletivo no momento mesmo em que ela ocorre. De fato, os atos coletivos dos quais nos fala são em boa medida contemplados na sua importância sociológica com diversos dados da observação direta das práticas e das interações efetuadas por visitantes durante exposições de artes plásticas que pude analisar. 
Alguns sentidos

Ao longo de alguns anos observei sistematicamente o comportamento do público de exposições de arte de centros culturais e museus de arte de diversas cidades. Concentrei minha pesquisa no Centro Cultural Banco do Brasil Rio de Janeiro e no Centro Dragão do Mar de Arte e Cultura, em Fortaleza, Ceará. ${ }^{15}$ Da etnografia das exposições pude derivar dados que nos permitem situar perguntas acerca do significado social dessa presença do público noutro campo de preocupações diferente daquelas voltadas para dimensões políticas da chamada popularização da cultura.

Uma parte significativa de centros culturais e de museus de arte que têm algumas de suas características, como vimos, estão situados em locais centrais de grandes cidades e oferecem exposições gratuitas ou a preços baixos, o que garante acesso de população numerosa e heterogênea, muitas das vezes desejosa de também ter acesso ao prédio, a seus teatros, shows, e a outros de seus espaços e eventos. Muitas dessas instituições, além disso, promovem também, por meio de setores educativos, investimento sistemático na presença nas exposições de diversos públicos, sobretudo de estudantes e de seus professores, especialmente de escolas públicas, afluxo que conta em muitos casos com visitas monitoradas, fornecimento de material educativo, atividades com alunos e professores sobre as exposições, e mesmo transporte das escolas para os centros culturais. Trata-se de público mais e mais diversificado e composto por indivíduos que nem sempre tiveram como prática esse contato com o espaço, com os agentes e com os objetos apresentados nas exposições. Em muitas circunstâncias, constatei que o deslocamento de jovens para a exposição consistia na sua primeira experiência fora do seu bairro ou do seu distrito. Lançar a pergunta a respeito do significado, para o público, de experimentar esse contato, de ocupar esse espaço, corresponde à indagação sobre novas experiências estéticas e de efetiva construção, pela população, do que costumamos chamar de arte. De outro lado os dados da pesquisa etnográfica nos levam tam-

\footnotetext{
${ }^{15}$ Em 1998 comecei a fazer observações sobre o comportamento do público em exposições de arte, a maior parte das vezes em centros culturais. Primeiro, até 2000, concentrei observações no público de exposições do Centro Cultural Banco do Brasil Rio de Janeiro, e, de 2001 a meados de 2002, em exposições do Centro Dragão do Mar de Arte e Cultura.
}

Horizontes Antropológicos, Porto Alegre, ano 14, n. 29, p. 257-278, jan./jun. 2008 
bém a imaginar que muitas das formas da população participar hoje da construção do que entendemos por arte, na verdade, já poderia estar discretamente existindo no seio de eventos que concebemos como altamente convencionais na sua presença em museus, especialmente nos solenes museus de arte.

A observação de recorrências e minúcias dessas experiências coletivas de entrar em contato com produtos de artes plásticas em locais públicos, nos permite assinalar especificidades importantes das artes plásticas e da exposição de seus objetos. Mas, em um outro plano, resultados da pesquisa etnográfica propiciam um alargamento de formas por vezes muito automatizadas de pensarmos a experiência da população com outros produtos artísticos, o que ultrapassa consideravelmente o âmbito desse trabalho, mas que têm informado e acompanhado minha investigação. De fato, as exposições de artes plásticas são situações sociais baseadas em referenciais espaço-temporais singulares, se comparadas às formas de apresentação de produtos artísticos próprias de outras tradições artísticas, como os espetáculos de dança ou teatrais, os shows, concertos musicais, leituras. ${ }^{16}$ No espaço de uma exposição o público pode, no limite, permanecer o tempo que quiser, o que, por exemplo, ao assistir um filme ou um recital de poesia é inviável. Essa autonomia do público das artes plásticas permite que uma variação significativa de experiências tenha lugar, ou que se intensifique, durante uma exposição, os indivíduos podendo demorar-se nela segundos ou horas, dependendo de seus desejos e possibilidades. Nas exposições de arte há também relativamente uma grande autonomia do público quanto ao modo como ocupa o espaço, podendo deslocar-se de uma para outra obra, voltar às que considera interessantes, ou passar pela exposição mantendo distância maior ou menor frente ao que está sendo apresentado. Essa flexibilidade também favorece uma variabilidade importante de experiências de se estar em uma exposição, o que não encontramos de modo tão acentuado durante a apresentação, por exemplo, de um espetáculo de dança, ou em uma sessão de cinema, quando todo o público costuma ocupar um lugar fixo ao longo do tempo, estabelecido mais que tudo pela obra, em que permanece nele. Nas exposições de objetos de arte, essa possibilidade especial, de o público ter autonomia em relação à ocupação do espaço e à manipulação do tempo de permanência nelas, dá ocasião a muitas interações e práticas sociais nem sempre computadas nas análises acerca do significado da presença do público nessas exposições.

\footnotetext{
${ }^{16}$ Em Dabul (2005) desenvolvo com mais vagar este e os pontos que seguem
} 
Como vimos, fazendo eco a questões dos atores sociais envolvidos com a gestão e a produção artísticas, com muita freqüência as exposições de arte são abordadas por cientistas sociais a partir da preocupação a respeito de como as obras são "recebidas", compreendidas e/ou "produzidas" pelos que têm contato com elas. A unidade "um indivíduo observando uma obra" costuma ser acionada para que essa reflexão seja desenvolvida, uma exposição, em linhas gerais, consistindo em situação na qual daquele conjunto de indivíduos - o público - cada um entrará em contato com cada obra exposta (que conterá mensagens e significados veiculados pelo artista que a confeccionou ou pelo curador que a apresentou naquela exposição). Esses supostos acerca da experiência do público, contudo, podem ser confrontados com a observação do que, de fato, é experimentado ao se estar em uma exposição de arte como as que temos visto serem promovidas por centros culturais freqüentados por público numeroso e heterogêneo.

Em primeiro lugar, ao contrário do que se infere com o foco no contato de cada indivíduo com uma obra, estar nas exposições não é uma prática individual. Nessas exposições os visitantes em geral chegam e permanecem boa parte do tempo agrupados, a partir de relações sociais estabelecidas noutro tempo e lugar - parentesco, amizade, vizinhança, coleguismo, de trabalho, de militância, de prática religiosa, etc. Por conta disso, a exposição de arte consiste em espaço e tempo ao longo dos quais indivíduos interagem, atualizando essas relações sociais significativas: amigos conversam, casais trocam carícias, estudantes preparam em colaboração tarefas solicitadas por professores, pais convivem com seus filhos, turistas mais uma vez conhecem novos lugares e pessoas juntos. Além disso, muito raramente indivíduos permanecem sozinhos em algum dos espaços das exposições, mesmo quando se dirigem sem acompanhantes a elas. Na verdade, interagem com outros visitantes que estão na exposição, e também com relações públicas e seguranças, que são atores sociais fixos nesses espaços. Por essa razão, as exposições de arte são situações sociais, ${ }^{17}$ conformadas por interações sociais significativas e extremamente variadas estabelecidas pelos que estão presentes nelas, o que demarca uma forma de análise que nos traz diversos outros elementos para pensarmos sobre como o público as experimenta, e sobre o que ocorre para além e, muitas vezes junto, do seu contato com obras de arte.

${ }^{17}$ Utilizo aqui o conceito de situação social proposto por E. Goffman (1981). 
A observação de obras não é, de fato, uma prática isolada, efetuada a seco nas exposições de arte. Nelas, a maioria dos indivíduos faz muitas outras coisas além de observar obras. Os visitantes, como vimos, namoram, brincam, estudam, conversam, caminham, dão uma olhada na exposição, etc. E mesmo a observação da obra, prática que com certa freqüência acionam para explicar a razão de estarem ali, é mesclada com outras: por exemplo, observam esculturas enquanto conversam, brincam, convivem. É também prática que a rigor compreende e pode ser decomposta em outras - deslocar-se em direção à obra, situar-se em local que possibilite alcançá-la com os olhos, voltar sua atenção para ela. Tais práticas costumam transpassar-se por outras, serem efetuadas coletivamente, e estarem submetidas à situação conformada pela composição social de uma parte da exposição naquele determinado momento: cheia ou vazia, agitada ou tranqüila, com mais crianças ou mais adultos, com brincadeiras, comentários, interesses voltados para a obra em questão ou não.

Da mesma maneira, podemos tratar a produção de significado a respeito das obras como prática coletiva, igualmente permeada por outras práticas sociais que têm lugar por meio de interações entre os que estão na exposição. Assim, a "descoberta" do que um artista teria desejado comunicar com uma obra configura-se com muita freqüência em jogo, em prática flexível e prazerosa, propiciada pela conversa. Por isso, essa "leitura” das intenções dos artistas pode acionar e aglutinar elementos oriundos de outras experiências comuns por exemplo algo vivido noutro tempo pelos atores sociais juntos ou não, assuntos outros, ou ocorrências ali naquele ambiente que não dizem respeito diretamente ao que o artista teria querido “dizer” - alguém que passa, algo que algum outro visitante comenta. A avaliação das obras, anunciar gostar ou não delas, considerá-las ou não arte, também é prática difundia e submetida muitas vezes à interlocução entre os visitantes durante a visita.

Pensarmos as exposições como situações sociais onde e quando as mais diferentes interações e práticas sociais têm lugar para além da própria observação da obra já nos remete para um conjunto vasto de itens a serem considerados ao tratarmos das determinações e repercussões dessas experiências da população de contato com objetos apresentados como artísticos. Mas, além disso, temos que atentar para o fato de que a própria observação não é prática dirigida apenas para obras de arte, os indivíduos também observando o ambiente, as etiquetas, eventuais mediadores, os outros visitantes que estão naquele espaço naquele momento, especialmente aqueles com os quais se dirigiram 
para a exposição. Na verdade, trata-se de experiência de alternância e conjugação, de um lado, de atenção em relação às obras e demais itens fixos e semifixos ${ }^{18}$ com os quais deparam nas exposições, e, de outro, de atenção em relação às interações sociais que estabelecem. Longe de se situar somente na construção do sentido das obras expostas, o significado da experiência do público nessas exposições está em grande medida vinculado ao compartilhamento das práticas por meio das quais efetua sua visita.

Por se tratar de experiência coletiva com esses atributos, o público muitas vezes a caracteriza como diversão. Distancia-se, desse modo, do que costuma ser preconizado por boa parte dos atores sociais envolvidos com a administração e manutenção das instituições que abrigam e promovem exposições de arte, os centros culturais e museus de arte, bem como dos que estão diretamente envolvidos com sua concepção e implementação, como curadores, cenógrafos e arte-educadores. C. Duncan (2000) aponta que historicamente esses atores sociais situam suas concepções acerca do próprio espaço das exposições, e suas intenções a respeito de sua promoção, em posições que variam entre dois pólos: o de espaços de exposição como favorecedores de experiências estéticas ou de experiências pedagógicas. De fato, em continuidade com essas concepções, cientistas sociais tendem a tomar as experiências do público em exposições de arte como caracterizadas ou pela singularidade e solenidade da contemplação estética, ou pelo aprendizado a respeito de sociedades, momentos históricos, estilos artísticos, vidas de artistas e outras realidades por meio do contato com objetos de arte. Como indica Duncan, é possível tomar o próprio espaço da exposição como ritual, propício para a experiência liminal, de suspensão da ordenação e das regularidades da vida cotidiana, o que evidências empíricas sustentam ser procedimento interessante. Contudo, compreender o que é realmente experimentado pelo público contribui para qualificar a eventual excepcionalidade do tempo e do espaço do público de exposições, que, como pretendo ter indicado, não se reduzem, ou não oscilam apenas entre a experiência educativa e a contemplativa.

${ }^{18}$ Ver em E. Hall (1989) a descrição dessa forma de abordar o espaço socialmente construído e apropriado.

Horizontes Antropológicos, Porto Alegre, ano 14, n. 29, p. 257-278, jan./jun. 2008 


\section{Observacoões, conversas finais}

Enfocar na maneira por meio da qual os indivíduos, juntos, efetivamente experimentam as exposições de artes plásticas nos sensibiliza para levarmos em conta e incorporarmos em nossas análises elementos normalmente considerados “de fora” da experiência artística - como comentários que não dizem respeito a obras expostas, brincadeiras, carícias, conversas que acompanham eixos que apenas tangenciam o que é exposto, anotações que estudantes fazem para entregar depois para seus professores avaliarem. Esses elementos não somente são extensamente verificados nas práticas do público no decorrer das exposições, como também costumam envolver procedimentos efetuados coletivamente (na colaboração direta entre atores sociais e/ou na co-presença deles) e significativos o bastante para comporem em extensão considerável a experiência do público durante sua permanência nas exposições de objetos de arte, definindo mesmo e atribuindo sentido a ela. Se temos ou aquele modelo contemplativo ou o modelo educativo de museu como referência para pensar essa presença do público, dificilmente constataríamos o tipo de experiência que realmente tem lugar nas exposições de arte. Ao invés, tenderíamos a computar ausências, distanciamentos desses modelos que, ao que parece, não dão conta de uma forma corrente de se ter contato com as artes plásticas que tem sua origem, como vimos, atribuída à criação do Beaubourg, mas que parece atualizar feitios de experiências da população com objetos de arte muito próximos à sua presença em outras formas de diversão.

A apropriação, para a compreensão do significado dessas experiências artísticas em centros culturais, de práticas normalmente refugadas do campo de estudo e definição da arte, considerando-as interiores à experiência artística, não faz com que se deva, por compromisso com o alcance de seus desdobramentos ou simetria lógica, incorporar enquanto tais aqueles elementos de objetos, digamos, ao mesmo tempo "não-artísticos" e mais amplos, como o lazer, a cidade, o espaço público, a luta pela cidadania, a pós-modernidade, a globalização etc. Talvez seja o caso de apenas tratar essas práticas a princípio "de fora” - brincar, namorar, dar só uma olhadinha na exposição - como práticas da mesma natureza daquelas consideradas em geral como as próprias da experiência artística, e da experiência estética, como observar e tentar entender o significado das obras expostas, voltando a atenção para elas - o que se afasta de modo considerável do suposto e enfatizado amplamente pelas 
análises sociológicas (e não apenas por elas) sobre o significado social do afluxo do público a exposições de artes plásticas, que apresentei anteriormente. Assim, abordar essas práticas “externas” dentro mesmo do fenômeno artístico, permite aumentarmos a extensão desse fenômeno, por assim dizer, para dentro, ou por dentro, considerando de fato que há cadeias de procedimentos que se entrecruzam e constroem o significado dessas experiências para muito além do significado das obras que são eventualmente observadas no seu desenrolar.

Lidamos, contudo, com uma série de obstáculos para o reconhecimento dessa natureza social da experiência artística, e um deles é tendermos a pensar no público como somatório de indivíduos. Essa maneira de conceber o público chega a tomar a forma de proposição sobre o público moderno em trabalhos de pesquisadores como Norbert Elias (1995), ele mesmo sensível à relevância sociológica das interações sociais quando descreve, dentre outros fenômenos, o público da corte para o qual Mozart compunha e executava suas músicas. Ainda, tratar, como é feito por muitos e importantes estudos sociológicos que demonstraram a determinação social de diversos aspectos naturalizados da arte, o público como vazado por seu pertencimento a categorias sociais, ou qualificar o conjunto de indivíduos considerados como público por meio de diferentes atributos que os localizariam nessa ou naquela categoria, estrato, grupo, segmento, classe social, consistem em operações que, no caso da investigação do que de fato é experimentado por esse público nas situações que têm lugar nas exposições de arte nos centros culturais, podem resultar justamente em paralisar nossas preocupações a esse respeito.

Sublinhar o que os indivíduos efetivamente fazem, e juntos, quando se deslocam para lugares que se abrem, dentre outras coisas, para a apresentação de objetos artísticos, traz também certos incômodos frente a algumas das tênues, mas aparentemente óbvias, fronteiras da arte que muitas vezes construímos para abordá-la como fenômeno social. Talvez também entre nós a arte não esteja tão separada de esferas da vida social que não a estética, para não dizer a sublime; ou a educativa, para não dizer a direta ou inequivocamente políti$c a$. Divertir-se em uma exposição, dando continuidade a experiências e práticas sociais, e por meio de interações sociais importantes, traz para o centro da arte o namoro, a brincadeira, o estudo, a conversa, e tantas outras e tão heterogêneas vivências que em geral preferimos classificar como distantes ou mesmo inadequadas se o assunto são objetos que acreditamos serem dotados da capacidade de suscitar sensações, insights ou conhecimentos excepcionais. Quem sabe as festas, as feiras, as praças, ou os espetáculos populares em 
locais públicos não nos dêem elementos para compreender esse deslocamento promovido por instituições e por parcela cada vez mais numerosa da população em direção ao que convencionamos tentar gostar e chamar de arte.

\section{Referências}

BARBOSA, Andréa Claudia M. Marques. MASP: um museu e seu público. Dissertação (Mestrado em Antropologia Social)-Programa de Pós-Graduação em Antropologia Social, Museu Nacional/Universidade Federal do Rio de Janeiro, Rio de Janeiro, 1994.

BARBOSA, Ana Mae. Arte-educação em um museu de arte. Revista da USP, v. 2, p. 125-132, jun./jul.ago. 1989.

BOURDIEU, Pierre. Gostos de classe e estilos de vida. In: ORTIZ, Renato (Org.). Pierre Bourdieu: sociologia. São Paulo: Ática, 1983. p. 82-121.

BOURDIEU, Pierre; DARBEL, Alain. L'amour de l'art: les musées d'art européens et leur public. Paris: Minuit, 1969.

BURKE, Peter. Cultura popular na Idade Moderna. São Paulo: Companhia das Letras, 1989.

CARVALHO, Rosane Maria R. de. O público invade os museus - é uma febre que se propaga? In: MUSEU EM TRANSFORMAÇÃO: as novas identidades dos museus. Rio de Janeiro: Museu da República, 1999. p. 163-167. (Cadernos de Memória: Cultural 4).

CENTRO CULTURAL BANCO DO BRASIL. Relatório de atividades. Rio de Janeiro, 1995.

CENTRO CULTURAL BANCO DO BRASIL. Arte, cultura e cidadania: Caderno IV: Programa Educativo. Rio de Janeiro, mar.jul. 2003.

DABUL, Lígia. O público em público: práticas e interações sociais em exposições de artes plásticas. Tese (Doutorado em Sociologia)-Programa de Pós-Graduação em Sociologia, Universidade Federal do Ceará, Fortaleza, 2005.

DE CERTEAU, Michel. A cultura no plural. Campinas: Papirus, 1995. 
DUNCAN, Carol. Civilizing rituals: inside public art museums. London: Routledge, 2000.

ELIAS, Norbert. Mozart: sociologia de um gênio. Rio de Janeiro: Zahar, 1995.

GARCÍA CANCLINI, Nestor. Culturas híbridas: estratégias para entrar e sair da modernidade. São Paulo: Edusp, 1998.

GIRAUDY, Daniele; BOUILHET, Henri. O museu e a vida. Belo Horizonte: Editora da UFMG, 1990.

GOFFMAN, Erving. Engagement. In: WINKIN, Yves (Ed.). La nouvelle communication. Paris: Seuil, 1981. p. 267-278.

GONDIM, Linda M. P. Desenho urbano e imaginário sócio-espacial da cidade: a produção de imagens da “moderna” Fortaleza no Centro Dragão do Mar de Arte e Cultura. Relatório da pesquisa submetido à Fundação Cearense de Amparo à Pesquisa (Funcap). Fortaleza, 2000. Mimeografado.

GONÇALVES, Lisbeth R. Entre cenografias. São Paulo: Edusp, 2004.

HALL, Edward. A dimensão oculta. Rio de Janeiro: Francisco Alves, 1989.

HANSEN, Karla. Programa Educativo do CCBB: arte, cultura e cidadania. Portal da Educação Pública. 5 nov. 2003. Disponível em: <http:// www.educacaopublica.rj.gov.br/jornal/materia.asp?seq=148>. Acesso em: 2 out. 2007.

HEINICH, Nathalie. La sociologie de l'art. Paris: La Découverte, 2000.

HOOPER-GREENHILL, Eilean. Counting visitors or visitors who count?. In: LUMLEY, Robert (Ed.). The museum time-machine. London: Routledge, 1992.

KLABIN, Vanda Mangia. Centro de Arte Hélio Oiticica. Acervo: Revista do Arquivo Nacional, Rio de Janeiro, v. 11, n. 1-2, jan./dez. 1998.

LOUREIRO, Maria Lucia de N. M.. Webmuseus de arte: aparatos informacionais no ciberespaço. Ciência da Informação, v. 33, n. 2, p. 97-105, maio/ago. 2004. Disponível em: <http://www.ibict.br/cienciadainformacao/ include/getdoc.php?id=1090\&article=126\&mode=pdf $>$. Acesso em: 2 out. 2007. 
MELLO E SILVA, Maria Celina de. Centro cultural: construção e reconstrução de conceitos. Dissertação (Mestrado em Memória Social)Programa de Pós-Graduação em Memória Social, Universidade Federal do Estado do Rio de Janeiro, Rio de Janeiro, 1995.

MILANESI, Luis Augusto. Centro de cultura: forma e função. São Paulo: Hucitec, 1990.

PASSERON, Jean-Claude. O raciocínio sociológico: o espaço não-popperiano do raciocínio natural. Petrópolis: Vozes, 1994.

PIANO, Renzo; ROGERS, Richard. Plateau Beaubourg au Centre Georges Pompidou. Paris: Centre Georges Pompidou, 1987.

PRAZERES, Luciana Martins. Iniciativas culturais, espaços de desenvolvimento: o caso do Centro Cultural Banco do Brasil e do Ecomuseu do quarteirão cultural do Matadouro, Rio de Janeiro. Dissertação (Mestrado)Instituto de Psicologia, Universidade Federal do Rio de Janeiro, Rio de Janeiro, 1996. 